\title{
Fatty acid composition of vegetable oil blend and in vitro effects of pharmacotherapeutical skin care applications
}

\author{
M. Guidoni (iD) ${ }^{1}$, M.M. de Christo Scherer (ii) ${ }^{1}$, M.M. Figueira (ii) ${ }^{1}$, E.F.P. Schmitt (ii) ${ }^{1}$, \\ L.C. de Almeida (10) ${ }^{2}$, R. Scherer (i) ${ }^{1}, \mathrm{~S}$. Bogusz (i) ${ }^{2}$ and M. Fronza (i) ${ }^{1}$ \\ ${ }^{1}$ Programa de Pós-Graduação em Ciências Farmacêuticas, Laboratório de Produtos Naturais, \\ Universidade Vila Velha, Vila Velha, ES, Brasi \\ ${ }^{2}$ Instituto de Química de São Carlos, Universidade de São Paulo, São Carlos, SP, Brasil
}

\begin{abstract}
Vegetable oils have been used for a plethora of health benefits by their incorporation in foods, cosmetics, and pharmaceutical products, especially those intended for skin care. This study aimed to investigate the cutaneous benefits of a vegetable oil blend (VOB) formulation and its fatty acid composition. The anti-inflammatory activity was studied in macrophages of RAW 264.7 cells by investigating the release of nitric oxide (NO), superoxide anion generation $\left(\mathrm{O}_{2}^{-}\right)$, tumor necrosis factor-alpha (TNF- $\alpha$ ), and interleukin 6 (IL-6). ABTS cation radical scavenging capacity assay, ferric reducing antioxidant potential (FRAP), 2,2-diphenyl-1-picrylhydrazyl (DPPH), and NO free radical scavenging assays were used to evaluate the antioxidant activity. VOB was tested for its ability to stimulate fibroblast proliferation and migration using the scratch assay, and antibacterial activity by the microdilution test. The fatty acid profile of a freshly prepared VOB formulation was determined by gas chromatography before and after accelerated stability testing. Chemical composition of VOB revealed the presence of oleic acid (C18:1n-9; $63.3 \%$ ), linoleic acid (C18:2n-6; 4.7\%), and linolenic acid (C18:3n-6; $5.1 \%)$ as major mono- and polyunsaturated fatty acids. No changes in the organoleptic characteristics and fatty acid composition were observed after the accelerated stability test. VOB $100 \mu \mathrm{g} / \mathrm{mL}$ reduced the healing time by increasing the total number of cells in the wounded area by $43.0 \pm 5.1 \%$ compared to the negative control group. VOB also suppressed the pro-inflammatory TNF- $\alpha$ and IL-6 cytokines, and $\mathrm{NO}$ and $\mathrm{O}_{2}{ }^{-}$production in lipopolysaccharide-stimulated macrophage cells. In conclusion, the VOB formulation contributed to the improvement of current therapeutic strategies for cutaneous applications in skin care.
\end{abstract}

Key words: Vegetable oil blend; Skin care; Fatty acids; Anti-inflammatory; Nitric oxide; Scratch assay

\section{Introduction}

Due to a widespread lifestyle shift caused by a multitude of factors in the last years, there is a growing demand for natural products. The world is considered a rich source of natural products. Vegetable oils, which are obtained from many renewable resources, are getting more attention than ever due to the numerous health benefits. Moreover, vegetable oils have attracted a great interest for the development of natural and eco-friendly cosmetics $(1,2)$. The medicinal value is based on the bioactive fatty acids constituents that have multiple skin benefits and may produce definite physiological action on the human body (3-5).

Vegetable oils are composed primarily by triacylglycerols and a sparse amount of diacylglycerols and monoacylglycerols. They also contain phospholipids, free sterols, tocopherols, and tocotrienols, triterpene alcohols, hydrocarbons, and fat-soluble vitamins in small amounts. Fatty acids composition of vegetable oils is classified according to the presence or absence of double bonds as saturated fatty acids (without double bonds), monounsaturated fatty acids (with one double bond), and polyunsaturated fatty acids (with more than two double bonds). The chain length and degree of unsaturation may have great influence on the chemical biological properties of these compounds. In addition, genetic and environmental factors can determine the proportions of saturated and unsaturated fatty acids present in vegetable oils $(1,6)$.

Wound healing is a natural process in which the body responds to an injury to protect itself from the outer environment while skin repair occurs simultaneously (7). Wound healing runs in three basic phases: inflammatory, proliferative, and maturation (8). After skin injury, the

Correspondence: M. Fronza: <marcio.fronza@uvv.br>

Received October 9, 2018 | Accepted December 6, 2018 
wound healing process begins immediately with clotting formation at the wound site by platelet aggregation and vasoconstriction. The pro-inflammatory cytokines and chemokines including interleukin-6 (IL-6) and tumor necrosis factor (TNF- $\alpha$ ) are released to activate inflammatory cells $(7,9)$. Neutrophils, macrophages, and fibroblasts are infiltrated to the wound site. Then, nitric oxide, oxygen free radicals, and matrix metalloproteinase are generated to prepare for the proliferation phase (10). The proliferation phase involves epithelialization and angiogenesis in which transforming growth factors and epidermal growth factor are important factors for stimulating proliferation, migration, and differentiation of fibroblasts and keratinocytes, forming extracellular matrix and collagen, and finally, tissue remodeling (9).

Vegetable oils are frequently used to treat wounds, mainly in developing countries. The most abundant fatty acids responsible for their therapeutic effect are oleic, linoleic, and linolenic acids (11-13). The non-saponifiable lipids are usually responsible for the anti-inflammatory and antioxidant effects of vegetable oils. Fatty acids are necessary for the maintenance of epidermal integrity and the water barrier of the skin. They are metabolic precursors of arachidonic acid and prostaglandins in the epidermis and important for regulation of cell division and epidermis differentiation $(2,14)$.

Therefore, our proposal was to develop a VOB formulation with vegetable oils of varying origin and fatty acid composition and to evaluate the therapeutic potential related to its in vitro antioxidant, anti-inflammatory, and antibacterial effects, and its capability to stimulate the proliferation and migration of fibroblasts.

\section{Material and Methods}

\section{Chemicals}

TNF- $\alpha$ and IL-6 ELISA kits were from eBioscience (USA). All other reagents were obtained from SigmaAldrich (USA). All solvents were of analytical grade and obtained from various commercial sources. The vegetable oils were purchased from SM Produtos Farmacêuticos (Brazil).

\section{Cell lines}

Mouse macrophages RAW 264.7 (American Type Culture Collection, ATCC ${ }^{\circledR}$ TIB- $\left.71^{\mathrm{TM}}\right)$ and murine fibroblasts (L929 cell line, ATCC ${ }^{\mathbb{R}}-\mathrm{CCL}^{\mathrm{TM}}{ }^{\mathrm{M}}$ ) (Cell Line Service, Brazil) were maintained in Dulbecco's modified Eagle's medium (DMEM) supplemented with $10 \%$ fetal bovine serum (FBS), $100 \mathrm{IU} / \mathrm{mL}$ penicillin, and $100 \mu \mathrm{g} / \mathrm{mL}$ streptomycin, at $37^{\circ} \mathrm{C}$, in a humidified atmosphere containing $5 \%$ $\mathrm{CO}_{2}$ (all Sigma, USA).

\section{Preparation of the vegetable oil blend}

The vegetable oil blend (VOB) was prepared by the direct mixture of flaxseed oil (15\%), blackcurrant oil (10\%), olive oil $(20 \%)$, rosehip oil (10\%), macadamia oil $(15 \%)$, and sunflower oil (30\%). The VOB was stored in an amber glass bottle in the absence of light and moisture at room temperature.

\section{VOB fatty acid profile}

VOB fatty acid methyl esters (FAME) were prepared by methylation with boron trifluoride (BF3) in methanol according to Joseph and Ackman (15). The FAME composition was determined by gas chromatography (GC-2014, Shimadzu, Japan), coupled with a flame ionization detector (FID). Fatty acids were identified by comparing the retention time using authentic standards of FAME (GLC85 reference standard, Nu-Chek-Prep, USA). The internal standard used was methyl tricosanoate (C23:0 reference standard, Nu-Chek-Prep). FAME were separated on a capillary column DB-5 $(30 \mathrm{~m} \times 0.25 \mathrm{~mm}$ I.D. $\times$ $0.25 \mu \mathrm{m}$ ) (Agilent Technologies, USA). Nitrogen was used as a carrier gas at $0.6 \mathrm{~mL} / \mathrm{min}$. The chromatographic conditions were injector $250^{\circ} \mathrm{C}$, split 1:50, injection volume $1 \mu \mathrm{L}$; oven: $100^{\circ} \mathrm{C}$ for $0.5 \mathrm{~min}$, followed by an increment of $3^{\circ} \mathrm{C} / \mathrm{min}$ to $260^{\circ} \mathrm{C}$; FID was maintained at $280^{\circ} \mathrm{C}$.

\section{VOB stability testing}

To estimate the stability of the VOB and the expiration date, accelerated stability testing was performed according to the Brazilian Health Regulatory Agency (16). The VOB sample was stored in a transparent, neutral glass bottle with a cover that guaranteed a proper seal avoiding loss of gases and evaporation to the medium. Then, the freshly prepared VOB was submitted to heating in an oven at $45 \pm 2^{\circ} \mathrm{C}$, alternating with cooling in the refrigerator at $5 \pm 2^{\circ} \mathrm{C}$, with cycles of $24 \mathrm{~h}$ each over 4 weeks. Organoleptic characteristics (color, odor, and appearance) and FAME profile were evaluated before and after the accelerated stability.

\section{DPPH free radical scavenging assay}

The DPPH scavenging activity of VOB $(1-2000 \mu \mathrm{g} / \mathrm{mL})$ was evaluated from the bleaching of the purple methanol solution of free radical DPPH according to Benevides et al. (17). The antioxidant activity is reported as $I C_{50}$ value $(\mu \mathrm{g} / \mathrm{mL})$ obtained from three independent experiments.

\section{Nitric oxide free radical scavenging assay}

The compound sodium nitroprusside is known to spontaneously generate nitric oxide, which interacts with oxygen to produce nitrite ions that can be estimated using the Griess reagent $(17,19)$. Briefly, the reaction mixture containing sodium nitroprusside in phosphate-buffered saline with or without the VOB was incubated at room temperature for $30 \mathrm{~min}$. Then, $150 \mu \mathrm{L}$ of incubated solution was mixed with $150 \mu \mathrm{L}$ of Griess reagent and the absorbance of chromophore formed was measured at $540 \mathrm{~nm}$ in an ELISA plate reader (SpectraMAX 190, Molecular Devices, USA). The results are reported as 
$\mathrm{IC}_{50}$ value $(\mu \mathrm{gmL})$. Experiments were carried out at least in triplicate.

\section{Ferric reducing antioxidant potential assay (FRAP)}

Antioxidant capability of VOB was estimated as described by Pulido et al. (18) with modifications by Benevides et al. (17). FRAP reagent was mixed with VOB or ethanol (for the reagent blank), incubated at room temperature for $10 \mathrm{~min}$, and then the absorbance was measured at $595 \mathrm{~nm}$ using a microplate reader (SpectraMax 190, Molecular Devices). The results are reported as $\mathrm{IC}_{50}$ value $(\mu \mathrm{g} / \mathrm{mL})$. Experiments were carried out at least in triplicate.

\section{ABTS cation radical scavenging assay}

The antioxidant activity was determined according to Re et al. (20). In 96-well microplates, $270 \mu \mathrm{L}$ of ABTS radical cation was mixed with $30 \mu \mathrm{L}$ of VOB $(1-2000 \mu \mathrm{g} / \mathrm{mL})$ (ethanol for blank) and allowed to react in the dark during $10 \mathrm{~min}$. Absorbance was measured at $734 \mathrm{~nm}$ using a microplate reader (SpectraMax 190, Molecular Devices). The results are reported as $I_{50}$ value $(\mu \mathrm{g} / \mathrm{mL})$. Experiments were carried out at least in triplicate.

\section{In vitro cytotoxicity}

Cellular viability was measured using the MTT assay according to Marques et al. (21). Macrophages RAW 264.7 and L929 fibroblast cells were incubated for $24 \mathrm{~h}$ in the presence or absence of VOB from 1-1000 $\mu \mathrm{g} / \mathrm{mL}$ concentration. Experiments were carried out at least in triplicate and results are reported as percentage of viable cells.

\section{In vitro wound healing (scratch) assay}

The in vitro scratch wound assay was carried out as previously described (24) with modifications (25). Briefly, fibroblasts were cultured to nearly confluent cell monolayers and then an artificial linear wound was made. Then, the monolayers were treated for $16 \mathrm{~h}$ with different concentrations of VOB $(1-200 \mu \mathrm{g} / \mathrm{mL})$. VOB was diluted in dimethyl sulfoxide (DMSO) and thereafter diluted in growth medium at the desired concentration. DMSO concentration in the wells was kept under $0.5 \%$ concentration. Platelet derived growth factor (PDGF) was used as positive control. After incubation, cells were fixed and stained with 2-(4amidinophenyl)-1-indole-6-carboxamidine (DAPI) and the cellular migration into the wounded area was quantified using CellC ${ }^{\mathbb{R}}$ software (Finland). Results are reported as percentage of cells that migrated and/or proliferated into the injured area compared to the untreated control group.

\section{Nitric oxide analysis in the supernatant of macrophage cell culture}

NO production was determined by measuring the amount of nitrite in lipopolysaccharide (LPS)-stimulated macrophages supernatant according to the Griess reaction (19) with minor modifications $(21,22)$. RAW 264.7 cells were treated with LPS $(1 \mu \mathrm{g} / \mathrm{mL})$ with or without VOB $(10-200 \mu \mathrm{g} / \mathrm{mL})$ for $24 \mathrm{~h}$. Next, the culture supernatant was mixed with Griess reagent (1:1) and incubated for $10 \mathrm{~min}$. Absorbance at $540 \mathrm{~nm}$ was measured in an ELISA plate reader (SpectraMax 190; Molecular Devices) and the inhibitory rates were calculated using a standard calibration curve prepared with sodium nitrite compared to LPS-stimulated control group.

\section{Quantitative colorimetric nitroblue tetrazolium assay}

The determination of intracellular superoxide anion production was evaluated in LPS-activated murine macrophages RAW 264.7 (21,23). Briefly, RAW 264.7 cells were seeded at a density of $2 \times 10^{5}$ cell $/ \mathrm{mL}$ in 96 -well plates and cultured in a $37^{\circ} \mathrm{C}$ humidified incubator with $5 \% \mathrm{CO}_{2}$ in air for $24 \mathrm{~h}$. Then, cells were stimulated with $1 \mu \mathrm{g} / \mathrm{mL}$ LPS in the presence or absence of increasing concentrations $(10-200 \mu \mathrm{g} / \mathrm{mL})$ of VOB for $24 \mathrm{~h}$. After incubation, the supernatant was removed and $100 \mu \mathrm{L}$ nitroblue tetrazolium (NBT) $(1 \mathrm{mg} / \mathrm{mL}$ ) was added to each well. The cells were washed with methanol and dried for $20 \mathrm{~min}$ at $37^{\circ} \mathrm{C}$. After incubation of $2 \mathrm{~h}$, the formazan crystals formed were dissolved with dimethyl sulfoxide (DMSO) and potassium hydroxide $(\mathrm{KOH})$. Absorbance was measured at $620 \mathrm{~nm}$, using a microplate reader (Multi-Mode Microplate Reader, FilterMax F5, Molecular Devices). The experiments were carried out at least in triplicate.

\section{Measurement of cytokines}

Quantification of TNF- $\alpha$ and IL- 6 production in the supernatant of LPS-activated murine macrophages RAW 264.7 after VOB exposure was determined by enzymelinked immunosorbent assay (ELISA) using specific antibodies (purified and biotinylated) and cytokine standards, according to the manufacturer's instructions (eBioscience, USA). Absorbance was measured at $450 \mathrm{~nm}$ in a microplate reader (Multi-Mode Microplate Reader, FilterMax F5, Molecular Devices). Cytokine levels are reported in pg and sensitivities were $>10 \mathrm{pg} / \mathrm{mL}$.

\section{Antibacterial activity}

The minimum inhibitory concentrations (MICs) of VOB were determined against the Gram-positive bacteria Staphylococcus aureus (ATCC 25923) and the Gram-negative bacteria Escherichia coli (ATCC 8739) by the standard NCCL method (NCCL, 2008), in a 96-well microtiter plate according to Benevides et al. (17). Different concentrations of VOB ranging from 62.5 to $2000.0 \mu \mathrm{g} / \mathrm{mL}$ were tested. The experiments were carried out at least in triplicate.

\section{Statistical analysis}

Data were analyzed by ANOVA and the post-hoc Tukey test, using GraphPad software (USA). KolmogorovSmirnov test was used to confirm the normality of data. All data are reported as the means $\pm S E$ or $S D$, and $P<0.05$ values indicated statistically significant differences. 


\section{Results}

\section{Fatty acid composition and stability of VOB}

Characterizations in the freshly prepared VOB and after the stability testing are reported as the percentage of total methyl esters and were analyzed by GC-FID. The VOB FAME composition is presented in Table 1 showing the presence of monounsaturated fatty acid (66.14\%) with oleic acid (C18:1n-9; 63.39\%) as the major lipid followed by the linoleic acid $(C 18: 2 n-6 ; 4.79 \%)$ and linolenic acid

Table 1. Relative percentages of fatty acid methyl esters (FAME) in freshly prepared vegetable oil blend (VOB) and after stability testing.

\begin{tabular}{lcc}
\hline FAME & $\begin{array}{c}\text { Fresh VOB } \\
(\%)\end{array}$ & $\begin{array}{c}\text { VOB after stability testing } \\
(\%)\end{array}$ \\
\hline Saturated & & \\
$10: 0$ & 0 & 0.02 \\
$12: 0$ & 0.32 & 0.37 \\
$14: 0$ & 0.32 & 0.33 \\
$15: 0$ & 0.02 & 0.02 \\
$16: 0$ & 15.05 & 15.33 \\
$17: 0$ & 0.12 & 0.12 \\
$18: 0$ & 5.98 & 5.99 \\
$20: 0$ & 0.89 & 0.88 \\
$22: 0$ & 0.66 & 0.06 \\
Total & 23.39 & 23.71 \\
Monounsaturated & & \\
$16: 01$ & 2.62 & 2.76 \\
$18: 1 n-9$ & 63.39 & 63.32 \\
$20: 1 n-9$ & 0.08 & 0.08 \\
$22: 1 n-9$ & 0.05 & 0.06 \\
Total & 66.14 & 66.23 \\
Polyunsatured & & \\
$18: 2 n-6$ & 4.79 & 4.00 \\
$18: 3 n-6$ & 5.09 & 4.24 \\
$20: 4 n-6$ & 0.06 & 0.06 \\
$20: 2 n-6$ & 0.08 & 0.05 \\
$20: 3 n-6$ & 0.68 & 0.67 \\
$20: 3 n-3$ & 0.02 & 0.02 \\
Total & 10.72 & 9.05 \\
\hline & &
\end{tabular}

(C18:3n-3; 5.09\%) as the major polyunsaturated fatty acids $(10.72 \%)$. The fatty acid profile of the sample did not significantly change after accelerated stability testing, and the characteristics of the polyunsaturated fatty acids were preserved. Moreover, no changes in color, appearance, odor, or viscosity were observed after the accelerated stability test. The results indicated that organoleptic characteristics of the VOB were markedly stable during the test period.

\section{VOB in vitro anti-oxidative effect}

Natural antioxidants play an important role in providing stability to vegetable oils hampering their oxidation. Antioxidant activity should not be concluded based on a single antioxidant test model, therefore, antioxidant activity of VOB was evaluated using four different chemical assays and the results are presented in Table 2. VOB exhibited only slight antioxidant activity $\left(\mathrm{IC}_{50} 233.7 \pm 1.48 \mu \mathrm{g} / \mathrm{mL}\right)$ estimated by its ability to reduce ferric iron $\left(\mathrm{Fe}^{3+}\right)$ to ferrous iron $\left(\mathrm{Fe}^{2+}\right)$ compared to tocopherol $\left(\mathrm{IC}_{50} 9.68 \pm\right.$ $2.30 \mu \mathrm{g} / \mathrm{mL}$ ). VOB did not exhibit any scavenging activity of DPPH, ABTS, and NO radical (Table 2) up to $2000 \mu \mathrm{g} / \mathrm{mL}$.

\section{VOB did not exhibit in vitro cytotoxicity}

Next, the colorimetric MTT assay was performed to determine the appropriate concentration of the blend, which would not affect cellular viability. VOB was tested in non-cancerous L929 fibroblasts and murine macrophages RAW 267.7 cells. VOB did not exhibit any cytotoxic effect against fibroblasts and macrophages compared to basal control (only cell culture medium, considered as $100 \%$ viability), showing 112 and $108 \%$ viability at the highest concentration tested of $1000 \mu \mathrm{g} / \mathrm{mL}$, respectively (Figure 1).

\section{In vitro cell migration/proliferation}

To evaluate in vitro cell migration/proliferation, the scratch assay was performed using fibroblasts. After $16 \mathrm{~h}$ in culture with VOB at different concentrations, the results showed a positive dose-dependent enhancement in fibroblast migration/proliferation in the artificial gap, especially at 100 and $200 \mu \mathrm{g} / \mathrm{mL}$ VOB concentration reaching values of $49.2 \pm 5.1 \%$ and $57.5 \pm 3.7 \%$, respectively, when compared to control cells $(6.2 \pm 2.0 \%$; $\mathrm{P}<0.05)$.

Table 2. Antioxidant activity of vegetable oil blend (VOB) determined by the chemical tests DPPH, ABTS, FRAP, and NO radical scavenging assay.

\begin{tabular}{lcrcc}
\hline Sample & \multicolumn{4}{c}{ Antioxidant activity $\left(\mathrm{IC}_{50} \mu \mathrm{g} / \mathrm{mL}\right)$} \\
\cline { 2 - 5 } & DPPH & FRAP & ABTS & NO \\
\hline VOB & $>2000.0$ & $233.7 \pm 1.5^{\mathrm{a}}$ & $>2000.0$ & $>2000.0$ \\
Tocopherol & $9.7 \pm 2.3$ & $4.8 \pm 0.2^{\mathrm{b}}$ & $6.5 \pm 0.5$ & \\
\hline
\end{tabular}

Data are reported as means $\pm S E(n=3)$. Experiments were carried out at least in triplicate. Different letters in the same column correspond to significant differences $(\mathrm{P}<0.05$, ANOVA and Tukey's post-hoc test). 
The significant stimulatory effects of VOB were comparable to PDGF $(59.4 \pm 6.8 \%)$ used as positive control (Figure 2).

\section{In vitro NO in macrophages}

LPS-stimulated macrophages induced significant NO production, which was significantly blocked by VOB in a dose-dependent manner (Figure 3). Reductions of $20.1 \pm$ $1.2 \%$ and $22.9 \pm 0.9 \%$ were observed in the macrophages supernatant after treatment with 100 and $200 \mu \mathrm{g} / \mathrm{mL}$ VOB concentrations, respectively.

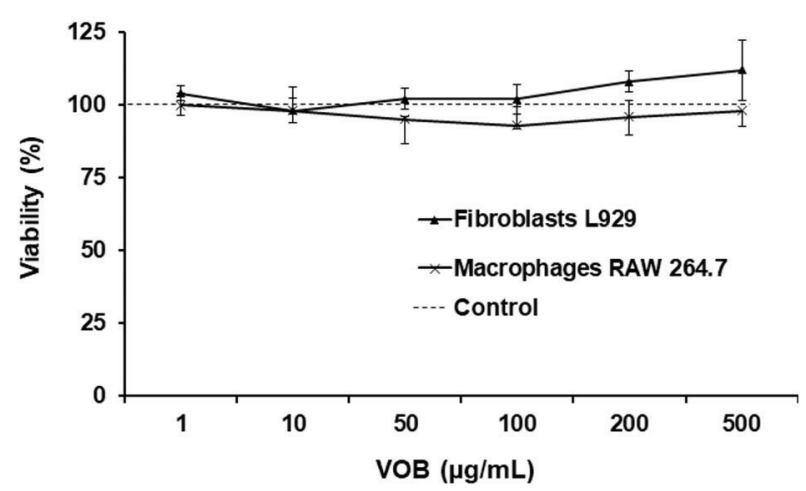

Figure 1. Cellular viability of fibroblasts and macrophages after $24 \mathrm{~h}$ exposure with 1 to $500 \mu \mathrm{g} / \mathrm{mL}$ vegetable oil blend (VOB) solution by the colorimetric MTT assay. Data are reported as mean \pm SE percentage of cellular viability compared to basal control cells of three independent experiments.

\section{Effect of VOB on the production of superoxide anion in LPS-stimulated RAW 264.7 macrophage cells}

The colorimetric NBT assay was used to measure the intracellular production of superoxide anion $\left(\mathrm{O}_{2}^{-}\right)$in LPSstimulated RAW 264.7 macrophage cells. As shown in

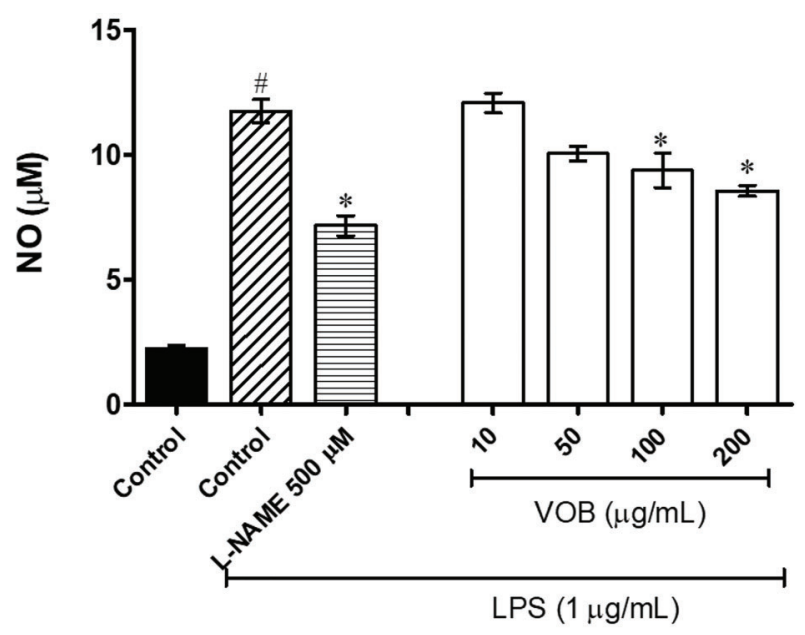

Figure 3. Inhibitory effects of vegetable oil blend (VOB) on nitrite production of lipopolysaccharide (LPS)-activated RAW 264.7 cells. LPS $(1 \mu \mathrm{g} / \mathrm{mL}$ ) with or without VOB (10 to $200 \mu \mathrm{g} / \mathrm{mL}$ ) was added to cells and nitrite concentration was measured by Griess reaction assay. Data are reported as means \pm SE of triplicate experiments. ${ }^{*} \mathrm{P}<0.05$ compared with the LPS-treated group. ${ }^{\#} \mathrm{P}<0.05$ compared with the unstimulated control group (ANOVA and the Tukey's post-hoc test).
A

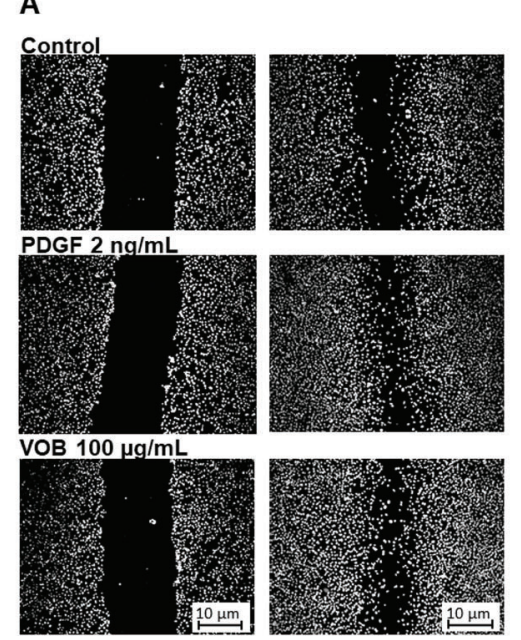

B

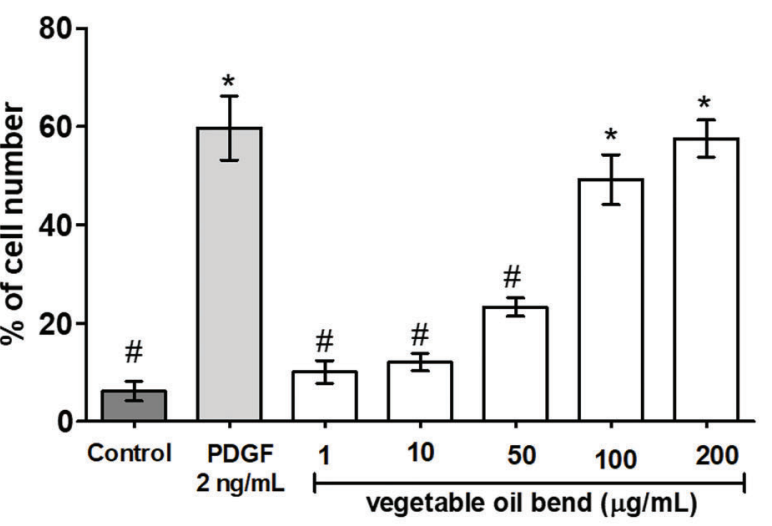

Figure 2. Vegetable oil blend (VOB) increased migration of fibroblasts in the scratch assay. Cells were treated with 1 to $200 \mu \mathrm{g} / \mathrm{mL}$ of $\mathrm{VOB}, 2 \mathrm{ng} / \mathrm{mL}$ of platelet derived growth factor (PDGF), or only with medium as control. A, Representative images were taken immediately after creating the wound $(0 \mathrm{~h})$ and after $16 \mathrm{~h}$ of incubation $(100 \times$ magnification; bar $10 \mu \mathrm{m})$. B, Percentage of cells after $16 \mathrm{~h}$ in the injured area compared to the scratch area at time zero $(0 \mathrm{~h})$. Data are reported as the mean \pm SE of two independent experiments. ${ }^{*} \mathrm{P}<0.05$ compared to control group; ${ }^{\#} \mathrm{P}<0.05$ compared to the positive control group (ANOVA and the Tukey's posthoc test). 


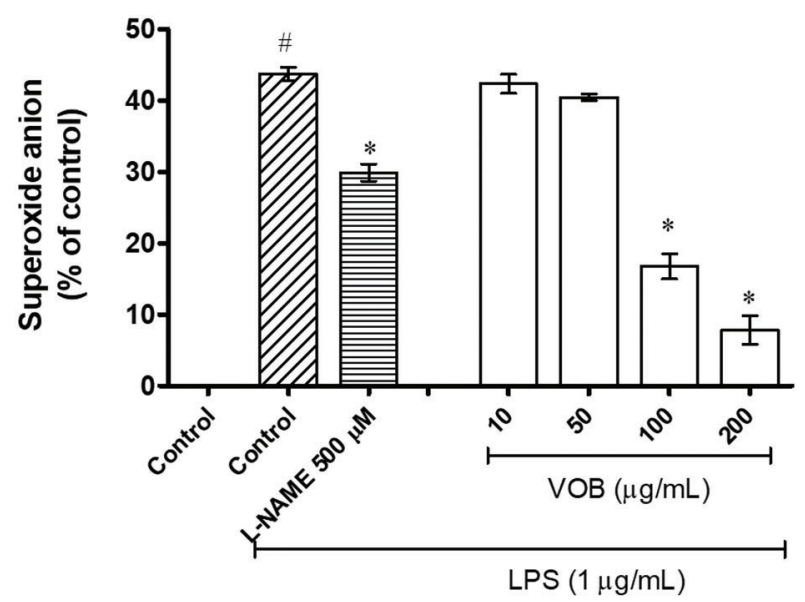

Figure 4. Inhibitory effects of vegetable oil blend (VOB) on intracellular superoxide anion production in lipopolysaccharide (LPS)-activated RAW 264.7 cells using the colorimetric NBT assay. Gallic acid (GA) was used as positive control. The level of superoxide anion in control cells was arbitrarily reported as zero. Data are reported as means $\pm S E$ of triplicate experiments. ${ }^{*} \mathrm{P}<0.05$ compared with LPS-treated cells. ${ }^{\#} \mathrm{P}<0.05$ compared with control (ANOVA and the Tukey's post-hoc test).

Figure $4, \mathrm{O}_{2}^{-}$production induced by LPS decreased significantly $(P<0.05)$ after 100 and $200 \mu \mathrm{g} / \mathrm{mL}$ VOB was added compared to the control group.

\section{Determination of cytokine production}

Concerning cytokines production, the effects of VOB on LPS-induced inflammation in RAW 264.7 macrophages were evaluated by measuring the production of TNF- $\alpha$ and IL-6 cytokines. As observed in Figure 5, stimulation with LPS for $24 \mathrm{~h}$ significantly induced the release of cytokines pro-inflammatory markers (TNF- $\alpha$ and IL-6) indicating that an inflammatory response was induced in the macrophages. Interestingly, VOB significantly reduced the production of IL- 6 and TNF- $\alpha$ production at 100 and $200 \mu \mathrm{g} / \mathrm{mL}$.

\section{Antibacterial activity of VOB}

Wound bacterial colonization presents a continuous challenge in the treatment of skin injuries and wound healing. Therefore, antibacterial activity of VOB was preliminarily assayed against the common Gram-positive Staphylococcus aureus bacteria and the Gram-negative Escherichia coli bacteria frequently hosted in cutaneous wounds (24). VOB exhibited only slight activity against $S$. aureus with a MIC value of $2000 \mu \mathrm{g} / \mathrm{mL}$ and did not exert any antibacterial activity against $E$. coli up to $2000 \mu \mathrm{g} / \mathrm{mL}$.

\section{Discussion}

In the present study, it was found that blending may be considered an economical and simple procedure to
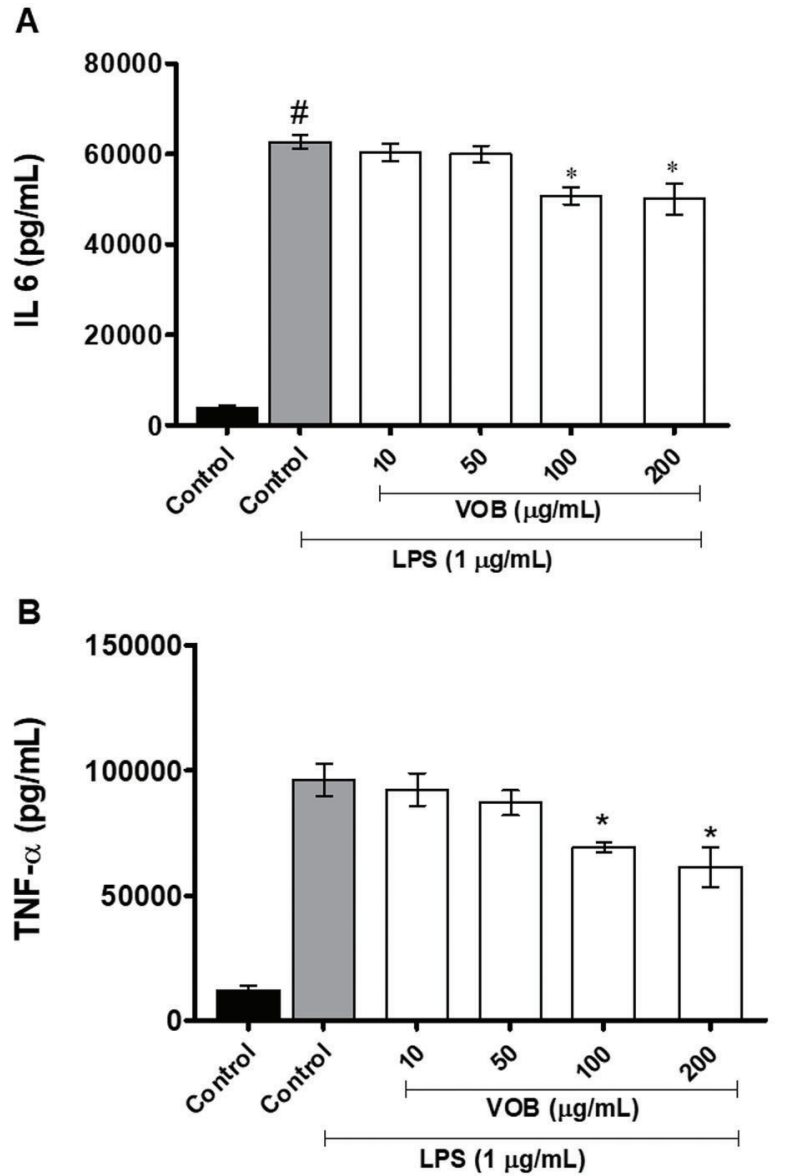

Figure 5. Effect of vegetable oil blend (VOB) on proinflammatory cytokine production in lipopolysaccharide (LPS)-stimulated macrophages. A, IL- 6 and B, TNF- $\alpha$ production was measured using ELISA kits. Data are reported as means \pm SE of two independent experiments. ${ }^{*} \mathrm{P}<0.05$ compared with LPS-treated cells. ${ }^{\#} \mathrm{P}<0.05$ compared with control (ANOVA and the Tukey's post-hoc test).

modify the fatty acid composition, enhancing the commercial application, and producing new specific products with a desired biological property, in general, at affordable prices (26). In general, natural vegetable oils have been used as topical therapy worldwide. They are easily accessible and a relatively inexpensive option for skin care including their therapeutic potential to positively influence cutaneous wound healing (12). Besides emollient properties, many natural oils possess specific compounds with antimicrobial, antioxidant, and anti-inflammatory activities. Moreover, it is possible to metabolize lipids derived from topically applied emollients and to utilize them as nutritional building blocks for the formation of a healthy and functional epidermal barrier $(2,11,12)$.

Unique characteristics of vegetable oil blends are important when considering their use for topical skin 
care. Different ratios of essential fatty acids are major determinants of the repair benefits of natural oils. Oils with a higher linoleic acid to oleic acid ratio have better barrier repair potential (12). Specifically, the quantities of fatty acids with healing effects are highlighted as oleic fatty acid, linoleic acid, and linolenic acid (27). The fatty acid profile of VOB exhibited predominantly the monounsaturated fatty acid, oleic acid (63.39\%), and the polyunsaturated fatty acids, linoleic acid (4.79\%) and linolenic acid $(5.09 \%)$. Thus, the fatty acid composition reinforces the potential therapeutic applicability for improving the natural skin-barrier function.

The fatty acids of the omega- 3 family (linolenic acid) and omega- 6 (linoleic acid) are of great importance for the inflammatory process, since they are not synthesized by de novo synthesis and are precursors of polyunsaturated fatty acids, such as eicosapentaenoic, docosahexaenoic, and arachidonic $(28,29)$. Linoleic acid exhibited an important chemotactic role for macrophages, contributing to the autolytic debridement of the wound bed by increasing the production of metalloproteins inducing granulation and accelerating the healing process (13). In light of this, VOB also demonstrated great stimulatory effects on the proliferative and migratory activity of fibroblasts contributing, therefore, to granulation tissue formation and re-epithelialization of the skin.

The inflammatory phase of wound healing normally leads to the release of biologically active mediators and oxygen-free radicals such as hydrogen peroxide, superoxide anion, and hydroxyl anion, and an excess of these agents is well known to cause tissue damage and hamper tissue repair $(9,10)$. In macrophage cells stimulated with LPS, known to be an endotoxin, the release of proinflammatory cytokines such as IL-6 and IL-1, and other inflammatory mediators such as $\mathrm{NO}(17,30)$ is induced. VOB was able to significantly suppress the production of these hazards of the healing process. The overproduction of NO has been reported to contribute to the pathogenesis of inflammatory diseases, including rheumatoid arthritis, atherosclerosis, pulmonary fibrosis, and unhealed wounds. Activated macrophages release into the extracellular medium several reactive oxygen species, including singlet

\section{References}

1. Lu C, Napier JA, Clemente TE, Cahoon EB. New frontiers in oilseed biotechnology: Meeting the global demand for vegetable oils for food, feed, biofuel, and industrial applications. Curr Opin Biotechnol 2011; 22: 252-259, doi: 10.1016/ j.copbio.2010.11.006.

2. Sarkar R, Podder I, Gokhale N, Jagadeesan S, Garg V. Use of vegetable oils in dermatology: an overview. Int J Dermatol 2017; 56: 1080-1086, doi: 10.1111/ijd.13623.

3. Balboa EM, Soto ML, Nogueira DR, González-López N, Conde E, Moure A, et al. Potential of antioxidant extracts produced by aqueous processing of renewable resources oxygen, superoxide anion, among others. VOB has been shown to be highly effective in inhibiting the production of these radicals, especially NO and superoxide anion, and inflammatory cytokines, proving to be a good alternative as an antioxidant and anti-inflammatory agent $(31,32)$.

Another significant problem with wounds is the high risk of infection. Therefore, the use of an antimicrobial agent during the healing process will help to reduce the risk of infection and the overall time for wound healing can be reduced significantly (28). Linoleic acid was proven able to inhibit the growth of Staphylococcus aureus by altering the synthesis of proteins, cell walls, nucleic acids, and cell membranes during division (13). Although VOB elicited only a discrete antibacterial action, it can be assumed that the topical use of VOB may protect cutaneous wounds from pathogenic bacteria and their harmful effects on wound healing.

In addition, chronic wounds of the skin present a painful, unsightly, and unpleasant sensory experience. VOB could be used to stimulate wound hydration, diminishing trauma during dressing changes. Besides, a hydrated wound favors the process of re-epithelialization, granulation, tissue formation, angiogenesis, fibroblast migration, collagen synthesis, and remodeling of injured tissue. Therefore, VOB should be used as a natural synergetic compound to treat skin wounds.

Altogether, this work highlights the role of a highly effective and low-cost vegetable oil blend, which may be used against inflammatory skin disorders or to treat skin injuries. In conclusion, more work should be done to increase our understanding of the mechanism by which VOB improved proliferation and migration of fibroblasts and altered proinflammatory and oxidative mediators in LPS-stimulated macrophages cells.

\section{Acknowledgments}

The authors wish to thank the Fundação de Amparo a Pesquisa do Espirito Santo (FAPES), Coordenação de Aperfeiçoamento de Pessoal de Nível Superior (CAPES), and Conselho Nacional de Desenvolvimento Científico e Tecnológico (CNPq) for financial support. for the formulation of cosmetics. Ind Crops Prod 2014; 58: 104-110, doi: 10.1016/j.indcrop.2014.03.041.

4. Begashaw B, Mishra B, Tsegaw A, Shewamene Z. Methanol leaves extract Hibiscus micranthus Linn exhibited antibacterial and wound healing activities. BMC Complement Altern Med 2017; 17: 337, doi: 10.1186/s12906-017-1841-x.

5. Zielińska A, Nowak I. Abundance of active ingredients in seabuckthorn oil. Lipids Health Dis 2017; 16: 95, doi: 10.1186/ s12944-017-0469-7.

6. Orsavova J, Misurcova L, Vavra Ambrozova J, Vicha R, Mlcek J. Fatty acids composition of vegetable oils and its 
contribution to dietary energy intake and dependence of cardiovascular mortality on dietary intake of fatty acids. Int J Mol Sci 2015; 16: 12871-12890, doi: 10.3390/ijms160 612871.

7. Napavichayanun S, Aramwit P. Effect of animal products and extracts on wound healing promotion in topical applications: a review. J Biomater Sci Polym Ed 2017; 28: 703-729, doi: 10.1080/09205063.2017.1301772.

8. Gurtner G, Werner S, Barrandon Y, Longaker M. Wound repair and regeneration. Nature 2008; 453: 314-321, doi: 10.1038/nature07039.

9. Schreml S, Szeimies R-M, Prantl L, Landthaler M, Babilas P. Wound healing in the 21st century. J Am Acad Dermatol 2010; 63: 866-881, doi: 10.1016/j.jaad.2009.10.048.

10. Fullerton JN, Gilroy DW. Resolution of inflammation: A new therapeutic frontier. Nat Rev Drug Discov 2016; 15: 551-567, doi: 10.1038/nrd.2016.39.

11. McDaniel JC, Belury M, Ahijevych K, Blakely W. Omega-3 fatty acids effect on wound healing. Wound Repair Regen. 2008; 16: 337-345, doi: 10.1111/j.1524-475X.2008.00388.x.

12. Vaughn AR, Clark AK, Sivamani RK, Shi VY. Natural Oils for Skin-Barrier Repair: Ancient Compounds Now Backed by Modern Science. Am J Clin Dermatol 2018; 19: 103-117, doi: 10.1007/s40257-017-0301-1.

13. Ferreira AM, de Souza BMV, Rigotti MA, Loureiro MR. The use of fatty acids in wound care: an integrative review of the Brazilian literature. Rev da ESC Enferm da USP 2012; 46: 752-760, doi: 10.1590/S0080-62342012000300030.

14. Pieper B, Caliri MH. Nontraditional wound care: A review of the evidence for the use of sugar, papaya/papain, and fatty acids. J Wound Ostomy Continense Nurs 2003; 30: 175-183, doi: 10.1067/mjw.2003.131.

15. Joseph JD, Ackman RG. Capillary column gas chromatographic method for analysis of encapsulated fish oils and fish oil ethyl esters: collaborative study. J AOAC Int 1992; 75: 488-506.

16. ANVISA. Guia de Controle de Qualidade de Produtos Cosméticos. Uma Abordagem sobre os Ensaios Físicos e Químicos. Agência Nac Vigilância Sanitária. 2008.

17. Benevides Bahiense J, Marques FM, Figueira MM, Vargas TS, Kondratyuk TP, Endringer DC, et al. Potential antiinflammatory, antioxidant and antimicrobial activities of Sambucus australis. Pharm Biol 2017; 55: 991-997, doi: 10.1080/13880209.2017.1285324.

18. Pulido R, Bravo L, Saura-Calixto F. Antioxidant activity of dietary polyphenols as determined by a modified ferric reducing/antioxidant power assay. J Agric Food Chem 2000; 48: 3396-3402, doi: 10.1021/jf9913458.

19. Green LC, Wagner DA, Glogowski J, Skipper PL, Wishnok JS, Tannenbaum SR. Analysis of nitrate, nitrite, and $\left[{ }^{15} \mathrm{~N}\right]$ nitrate in biological fluids. Anal Biochem. 1982; 126(1): 131138, doi: 10.1016/0003-2697(82)90118-X.

20. Re R, Pellegrini N, Proteggente A, Pannala A, Yang M, Rice-Evans C. Antioxidant activity applying an improved ABTS radical cation decolorization assay. Free Radic Biol
Med 1999; 26: 1231-1237, doi: 10.1016/S0891-5849(98) 00315-3.

21. Marques FM, da Costa MR, Vittorazzi C, Gramma LSDS, Barth T, de Andrade TU, et al. In vitro and in vivo antiinflammatory effects of Struthanthus vulgaris. Planta Med 2017; 83: 770-777, doi: 10.1055/s-0043-101916.

22. Dos Santos Gramma LS, Marques FM, Vittorazzi C, de Andrade TA, Frade MA, de Andrade TU, et al. Struthanthus vulgaris ointment prevents an over expression of inflammatory response and accelerates the cutaneous wound healing. J Ethnopharmacol 2016; 190: 319-327, doi: 10.1016/j.jep. 2016.06.050.

23. Choi HS, Kim JW, Cha YN, Kim C. A quantitative nitroblue tetrazolium assay for determining intracellular superoxide anion production in phagocytic cells. J Immunoass Immunochem 2006; 27: 31-44, doi: 10.1080/15321810500403722.

24. Liang CC, Park AY, Guan JL. In vitro scratch assay: a convenient and inexpensive method for analysis of cell migration in vitro. Nat Protoc 2007; 2: 329-333, doi: 10.1038/nprot.2007.30.

25. Fronza M, Heinzmann B, Hamburger M, Laufer S, Merfort I. Determination of the wound healing effect of Calendula extracts using the scratch assay with 3 T3 fibroblasts. J Ethnopharmacol 2009; 126: 463-467, doi: 10.1016/ j.jep.2009.09.014.

26. Hashempour-Baltork F, Torbati M, Azadmard-Damirchi S, Savage GP. Quality properties of sesame and olive oils incorporated with flaxseed oil. Adv Pharm Bull 2017; 7: 97-101, doi: 10.15171/apb.2017.012.

27. Pereira LM, Hatanaka E, Martins EF, Oliveira F, Liberti EA, Farsky SH, et al. Effect of oleic and linoleic acids on the inflammatory phase of wound healing in rats. Cell Biochem Funct 2008; 26: 197-204, doi: 10.1002/cbf.1432.

28. Misic AM, Gardner SE, Grice EA. The wound microbiome: modern approaches to examining the role of microorganisms in impaired chronic wound healing. Adv Wound Care 2014; 3: 502-510, doi: 10.1089/wound.2012.0397.

29. Kiecolt-Glaser JK, Glaser R, Christian LM. Omega-3 fatty acids and stress-induced immune dysregulation: implications for wound healing. Mil Med 2016; 181: 1165, doi: 10.7205/ MILMED-D-16-00273.

30. Vittorazzi C, Endringer DC, Andrade TU, Scherer R, Fronza M. Antioxidant, antimicrobial and wound healing properties of Struthanthus vulgaris. Pharm Biol 2016; 54: 331-337, doi: 10.3109/13880209.2015.1040515.

31. Dhavamani S, Poorna Chandra Rao Y, Lokesh BR. Total antioxidant activity of selected vegetable oils and their influence on total antioxidant values in vivo: a photochemiluminescence based analysis. Food Chem 2014; 164: 551555, doi: 10.1016/j.foodchem.2014.05.064.

32. Badea G, Lăcătuşu I, Badea N, Ott C, Meghea A. Use of various vegetable oils in designing photoprotective nanostructured formulations for UV protection and antioxidant activity. Ind Crops Prod 2015; 67: 18-24, doi: 10.1016/ j.indcrop.2014.12.049. 